\title{
Dynamic Activity Analysis Model Based Win-Win Development Forecasting Under the Environmental Regulation in China
}

\author{
Shiyi Chen* \\ Wolfgang Karl Härdle**
}

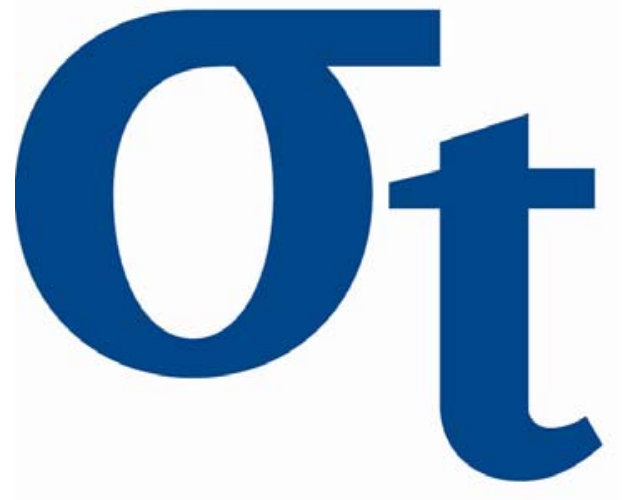

* Fudan University Shanghai, China

**Humboldt-Universität zu Berlin, Germany $\underline{v}$

This research was supported by the Deutsche Forschungsgemeinschaft through the SFB 649 "Economic Risk". 


\title{
DYNAMIC ACTIVITY ANALYSIS MODEL BASED WIN-WIN DEVELOPMENT FORECASTING UNDER THE ENVIRONMENTAL REGULATION IN CHINA
}

\author{
SHIYI CHEN ${ }^{\mathrm{a}^{*}}$ AND WOLFGANG K. HÄRDLE ${ }^{\mathrm{b}}$ \\ ${ }^{a}$ China Centre for Economic Studies, School of Economics, Fudan University, China \\ ${ }^{\mathrm{b}}$ Centre for Applied Statistics and Economics, Humboldt-Universität zu Berlin, Germany
}

\begin{abstract}
SUMMARY
Porter Hypothesis states that environmental regulation may lead to win-win opportunities, that is, improve the productivity and reduce the undesirable output simultaneously. Based on directional distance function, this paper proposes a novel dynamic activity analysis model to forecast the possibilities of win-win development in Chinese Industry between 2009 and 2049. The evidence reveals that the appropriate energy-saving and emission-abating regulation will result in both the improvement in net growth of potential output and the steadily increasing growth of total factor productivity. This favors Porter Hypothesis.
\end{abstract}

\section{Key Words:}

Dynamic Activity Analysis Model, Energy-Saving and Emission-Abating, Environmental Regulation, Win-Win Development

JEL Classification: D24, O47, Q25, Q32

\section{INTRODUCTION}

To achieve an agreement among countries to promissarily ababte dioxide carbon after the expiration of Kyoto Protocol in 2012, all countries began to launch a new round of negotiations. The negotiation is extremely difficult due to the dispute of abatement obligations and the worry of slowdown of economic growth, especially during the period of financial crisis. There was no substantial progress on how to extend the Kyoto Protocol in Copenhagen and Cancun climate conference in the past two years. Compared with the avoidance of global responsibility, however, many countries regard that the low-carbon economy will lay the foundation of future growth and invest much in green dimension in the stimulus packages to challenge the financial crisis. For example, the important component of American Recovery and Reinvestment Act proposed by President Obama is to develop renewable energy. The House of Representatives also passed the landmark American Clean Energy and Security Act in 2009 in order to make the renewable energy and low-carbon technique new economic driver. In 2009, UK also released the white papers of national strategy, Low Carbon Transition Plan, to 2020, for becoming a low carbon country: cutting emissions, maintaining secure energy supply and maximizing economic opportunities.

According to HSBC's report (Robins et al., 2009), with sizeable financial reserves and a tradition of long-term planning, in November 2008, China launched its RMB 4,000bn (USD584bn) package. Almost $40 \%$ of this is allocated to green themes, most notably rail, grids and water infrastructure, along with dedicated spending on environmental improvement. Elsewhere in Asia, South Korea has introduced a dedicated Green New Deal, with more than $80 \%$ allocated to environmental themes. The new American Recovery and Reinvestment Plan commits USD787bn

\footnotetext{
* Correspondence to: Shiyi Chen, School of Economics, Fudan University, Shanghai, 200433, China

E-mail: shiyichen@fudan.edu.cn
} 
to kick-start the economy, with USD94bn for renewables, building efficiency, low-carbon vehicles, mass transit, grids and water. Although the green component is smaller than China's, it is more broadly based, and the only plan with a real boost to renewables. The existence of substantial automatic fiscal stabilisers in Europe has meant that the EU stimulus is so far smaller in size. However, the climate change dimension is greater than in the USA, due to a focus on low-carbon investment in France, Germany and at the EU level.

So why do countries have totally distinct attitudes towards the same matter domestically and internationally? In fact, all countries are clear about the inevitability of energy saving and environment protection in the long run since it is crucial for the economic transformation and future competition in novel technology. Whereas in the short run, especially under the circumstance of financial crisis, energy-saving and emission-abating will use up the limited resources which may be put into other productions, slowing the pace of economy resuscitation. That is the reason why all the countries hesitate on the promise for the emission reduction in the international climate negotiation. As a matter of fact, there are also two opposite arguments on how energy saving and emission reduction may influence the economy in the academic field. On one side, Porter hypothesis argues that energy saving and emission reduction can bring the opportunities for win-win development, i.e. simultaneous improvements in both environmental quality and productivity, meeting both social and economic goals. On the other side, some scholars rise doubts on the existence of this win-win development because if it does exist it will be unnecessary for the government to impose extra environmental protective costs on the firms. Large number of researches focus on the empirical study of the existence of this win-win development possibility, which will be surveyed in Section 2 of this paper.

China is the 2nd largest energy consumer in the world, only inferior to the US. More specifically, the US and China are respectively the 1 st and 2nd largest coal consumers, which correspondingly makes the two countries top 2 greenhouse gases emitters in the world. And in 2007, China's carbon dioxide emission has exceeded the US, which brings China much abatement burden from the outside world. With the proposal of scientific outlook on development, energy saving and emission abating has also become the propeller of China's economic structural adjustment and transformation of development model (Cai, 2008). Hence, an in-depth analysis is needed on both the positive and negative effect of energy saving and emission reduction on China's economy, especially the output growth and productivity of the real economy after financial crisis. Searching for an optimal energy-saving and emission-abating path which can induce a win-win development for China in the following decades, a strategically critical period, is also a quite practical and edging issue, prompting the motivation for this paper research. As is known to all, industry as a major part of China's real economy is the primary origin of China's carbon dioxide emission. It counts for over 80 percent of the total amount of emission, which makes it the primal target of energy saving and emission abating. Whereas, China has been in the mid-industrialization process which is characterized by a booming heavy industry with large energy consumption and pollutant emission. Energy and emission intensive industries such as iron and steel, cement and chemistry industries will continue to play pivotal roles in future economic growth. Thus, we can foresee there will be more negative impact brought by energy-saving and emission-abating activities on China's industry, especially the heavy industry. All in all, a correct understanding of the relationship between energy \& environment, and industrial output \& productivity is tremendously meaningful for China's industrial economy and public decisions. This 
paper focuses on 38 sub-industries and proposes a dynamic version of activity analysis model (AAM) modified from the directional distance function (DDF) to examine the existence of Porter Hypothesis in China. Based on the proposed model, we also attempt to search for an optimal energy-saving and emission-abating path which could lead to the win-win development possibility for China's industry from now on to the 100th anniversary of the People's Republic of China.

This rest of this paper is organized as below: Section 2 surveys the empirical studies to examine the existence of Porter hypothesis; Section 3 designs the different energy-saving and emission-abating pathes, which will be added into the direction vector of DDF so as to extend the AAM into dynamic version; Section 4 measures the magnitude of these win-win opportunities among a set of sub-industries corresponding to different pathes designed in the former section to pin down an optimal path for China's industrial win-win development during 2009 and 2049; Section 5 conclude this paper.

\section{LITERATURE REVIEW}

In the recent 20 years, the relationship among energy, environment and economy (3E) has always been a focal topic of scholars and policy makers. The traditional established notion on environmental protection is that the extra costs government imposes on the firms can jeopardize their international competitiveness. Porter, however, first challenged this argument in his one-page paper published in 1991 (Porter, 1991). He regarded large energy consumption and pollutant emission as a form of economic waste and a sign of incompletion and inefficiency of resources using. In his opinion, the amelioration of this inefficiency will provide firms with the win-win opportunity of improving both the productivity and environment. And the efforts of environmental protection can help firms to identify and eliminate the production inefficiency and regulatory disincentives that prevent the simultaneous improvements in both productivity and environmental quality. Thus, whether these types of environmental policy initiatives are successful depends on the extent to which such inefficiencies are widespread in the sub-industries, particularly in the energy/pollution intensive industries. However, due to deficient management systems, firms are not aware of certain opportunities and that environmental policy might open the eyes. Porter and van der Linde (1995) further emphasized that properly designed environmental protection policy in the form of economic incentives can trigger innovation that may partially or fully offset the costs of complying with them. Such innovation offsets occur mainly because pollution regulation is often coincident with improved efficiency of resource usage and the inference is that stiffer environmental regulation results in greater productivity and competence. These arguments are titled as Porter hypothesis (Ambec and Barla, 2002). Admittedly, many scholars criticize Porter hypothesis, arguing that it is a fundamental challenge to efficient market hypothesis and neoclassical theory. They question why firms do not see these win-win opportunities by themselves, which at least implies that the argument does not have a general validity (Palmer et al., 1995; Jaffe et al., 1995; Faucheux and Nicolaï, 1998).

There are many empirical researches related to Porter hypothesis. Combining the idea of ecological economics on capital substitution and Porter Hypothesis, Karvonen (2001) workes on the development of Finland's capital intensive paper industry in the past 20 years, and reveals how the use of new technologies help the industry achieve a win-win situations and how human-made capital investments influence the quality of natural capital. Mohr (2002) derives results consistent with Porter's hypothesis by employing a general equilibrium framework with a large number of 
agents, external economies of scale in production and discrete changes in technology. The model shows that endogenous technical change makes Porter's hypothesis feasible. However, a policy that produces results consistent with Porter's hypothesis is not necessarily optimal. Nugent and Sarma (2002) uses an environmentally extended computable general equilibrium (CGE) model to analyze the case of India and finds that a thorough integration of economic, distributional and environmental policies can collectively "win" in achieving economic growth, distributional equity and environmental sustainability at the same time. Murty and Kumar (2003) estimate the output distance function of India's manufacturing industry using the stochastic parametric approach and come to the conclusion that the technical efficiency of firms increases with the intensity of environmental regulation and the water conservation efforts, which supports the Porter hypothesis about environmental regulation. Beaumont and Tinch (2004) find that the abatement cost curve methodology proves to be a valuable management tool in identifying barriers to achieving the win-win state, or at least win-draw scenario for industry and the environment, and also in providing future direction for the waste management strategy. Cerin (2006) supports Porter hypothesis and finds the private incentives to explore the win-win development by applying the Coase theorem that emphasizes transaction costs and property rights. This paper argues that strong public support is needed to create private incentives for exploring economic and environmental win-win innovations. Greaker (2006) provides some support for Porter hypothesis. The result that policy should be more stringent when a well-developed market for new abatement equipment does not exist clearly has a general appeal. The simulations show that environmental policy has very little effect on export marketshare as long as the price of pollution abatement equipment is decreasing in the stringency of environmental policy; thus, governments should a priori be less afraid of introducing a sufficiently stringent environmental policy. Managi (2006) tests the hypothesis that there are increasing returns to abating pollution. Empirical evidence on environmental risks in the US agricultural sector since 1970 support the existence of increasing returns. Kuosmanen et al. (2009) propose a new approach to environmental cost-benefit analysis (ECBA) which does not require prior valuation of the environmental impacts and is based on shadow prices, and conducts efficiency analysis of ten alternative GHG abatement timing strategies, taking into account the ancillary benefits. Groom et al. (2010) evaluate the impact of the Sloping Lands Conversion Programme (SLCP) on off-farm labour supply in China, and the results identify some support for the win-win hypothesis in the case of the SLCP, and how the targeting of the programme can be improved. Reddy and Assenza (2009) emphasize that climate protecting policies based on the market consideration can increase the opportunity of win-win development. In particular, the paper suggests the integration of climate policies with those of development priorities that are vitally important for developing countries and stresses the need for using sustainable development as a framework for climate change policies.

There are also a few papers whose conclusion is neutral or against Porter hypothesis. Boyd and McClelland (1999) construct efficiency measures based on Shephard's distance function and view it as a test of Porter hypothesis. The findings support aspects of both sides of Porter debate; that is, there is evidence of a win-win potential to increase production and reduce pollution as well as evidence of losses to potential output due to environmental constraints. Thus, comparing the estimates with other studies must be approached with caution, since there can be substantial differences in methodologies. Xepapadeas and De Zeeuw (1999) isolate two effects resulting from the introduction of a stricter environmental policy in the form of a tax on emissions: a productivity 
effect and a profit-emission effect. The results indicate that although a stricter environmental policy cannot be expected to provide a win-win situation in the sense of both reducing emissions and increasing profitability in an industry, you may expect increased productivity of the capital stock along with a relatively less severe impact on profits and more emission reductions, when the stricter policy induces modernization of the capital stock. By allowing for nonlinearities, Feichtinger et al. (2005) generalizes Xepapadeas and De Zeeuw (1999) and determines scenarios in which their results do not carry over. The paper also focuses more explicitly on learning and technological progress, and obtains that in the presence of learning, implementing a stricter environmental policy with the aim to reach a certain target of emissions reduction has a stronger negative effect on industry profits, which implies quite the opposite as to what is described by the Porter hypothesis.

As stated previously, theoretical and empirical research have provided arguments for both positions and have not been conclusive so far, which may be due to different data sets used, the regulatory regime in a country, the cultural setting, customer behaviour, the type of industries or size of companies analysed, the time span, etc. However, the main reason for the conflicting results of the various empirical studies may be the lack of a reasonable theoretical framework within which to investigate the links between environmental regulation and economic performance (Schaltegger and Synnestvedt, 2002). For example, the commonly used CGE model fits static analysis well but its dynamic extension in empirical study is still rather scarce and too simple; parametric macroeconometric model is restricted to its priori functional form and distribution assumption; environmental cost and benefit analysis needs the economic evaluation on environmental effects firstly which is a technical challenge itself; the analysis based on the theories of property rights, externality and transaction cost cannot soundly quantify the economic influence of environmental regulation; traditional Shepherd distance function cannot distinguish the different characteristics between two outputs of both GDP and pollution, and so on. Not until the presence of directional distance function do we find a reasonable framework to capture the difference between GDP and environmental pollution. DDF allows for the type of inefficiency that is typified by Porter hypothesis that increases desirable output while decreases undesirable output simultaneously, which means that DDF provides the most appropriate tool to examine Porter hypothesis. By employing two kinds of DDF based on the strong and weak disposability of pollution, respectively, proposed by Boyd et al. (2002), this paper attempts to measure the potential revenues and output loss, and corresponding change of production efficiency, technical progress and total factor productivity (TFP) resulted from energy-saving and emission-abating regulation. In order to forecast the win-win development possibility from now on to the year of 2049 and find the optimal environmental regulatory path, in particular, different energy-saving and emission-abating pathes with the time lag operator are introduced into direction vector of DDF to form a dynamic version of AAM. Such a methodology are described in Section 3.

\section{METHODOLOGY}

\subsection{Design the Energy-Saving and Emission-Abating Pathes}

Different energy-saving and emission-abating pathes will have obviously different impact on economy (Lee et al., 2007; Kuosmanen et al., 2009). This paper designs five energy-saving scenarios and nine emission-reducing scenarios, totally forty five policy pathes combination, and 
simulates their effect on the potential output and productivity in the future so as to look for the best regulatory path leading to a win-win development possibility for Chinese industry.

The design of energy saving scheme is based on the promissory targets to save energy stipulated in China's the eleventh five-year plan in 2006, i.e. decreasing the energy consumption per unit of GDP (energy intensity) by 20 percent during 2006 and 2010 (4 percent per year). In view of the possibility of easier realization, in fact, this paper just choose a lower value of 3 percent as the reduction rate annually for energy intensity. Based on this, if we assume that the averaged growth of China's gross industrial output value is likely to be one of the five possibilities $(4 \%, 6 \%, 8 \%, 10 \%$, and $12 \%)$ in the future, we can calculate that the corresponding average annual growth rate of energy consumption is $0.9 \%, 2.8 \%, 4.8 \%, 6.7 \%$ and $8.6 \%$, respectively ${ }^{1}$. Comparing with averaged annual $11.2 \%$ and $6 \%$ growth rate of industrial output and energy consumption, respectively, between 1981 and 2006 provided by Chen (2009), five growth possibilities for output and energy consumption set previously are moderate and very likely to be realized $^{2}$.

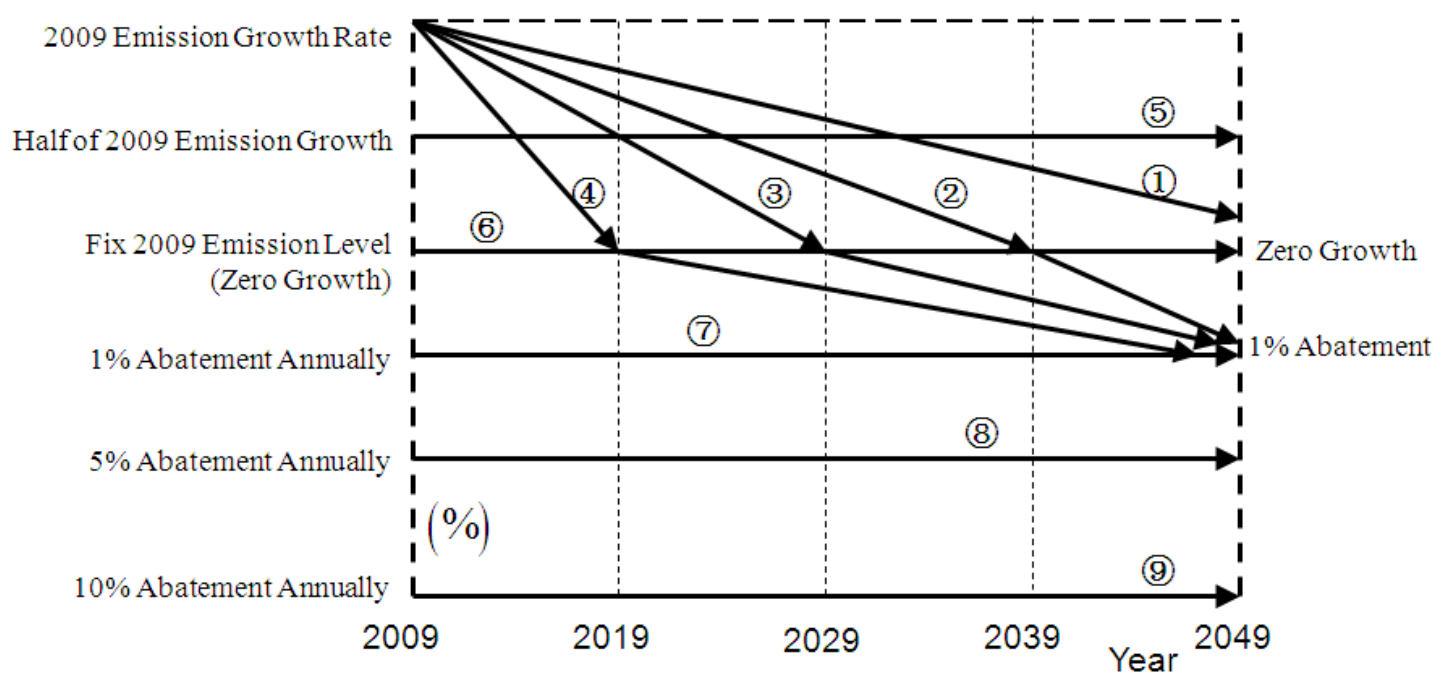

Figure 1. Design of Dioxide Carbon Abatement Pathes (1-9) for Chinese Industry (2009-2049)

This paper designs the scheme of emission reduction based on the principle from gradual reduction to sharp one, the former of which caters to the state condition that China is a developing country whose major task is to develop. The design is also attributable to the generalized understanding of emission abatement concept that emission reduction does not necessarily refer to the absolute decline in aggregate emission level and a declining emission growth rate or declining relative to $\mathrm{BaU}$ is also a type of emission abatement corresponding to the gradual or moderate principle. Therefore, as shown in Figure 1, the nine kinds of emission reduction pathes from

\footnotetext{
${ }^{1}$ The denominator of energy intensity, according to its definition, is GDP or value-added. In this paper, the gross industrial output value is chosen as the denominator to calculate the energy intensity; at all events, the calculated growth of energy consumption based on the decreasing rate of energy intensity, 3\%, and the growth of output, either value-added or gross industrial output value, is the same.

${ }^{2}$ For another example, Lin (2004) asserts that China is very likely to maintain around 8\% GDP growth rate, like the middle level of our specification, for another twenty or thirty years by adapting technological know-how from advanced countries at a lower cost. The growth of output and energy consumption is necessary for the economic development but their combination leading to around 3-4\% declining rate of energy intensity annually is the most important for the sustainable development in China, as concerned in this paper.
} 
moderatest to strongest abating intensity designed in this paper are listed below: 1 . The growth of dioxide carbon for different sub-industries evenly decreases from the respective growth rate of emission in the year of 2009 to zero growth in 2049, that is, the emission peak will appear in mid of this century; 2. The emission growth of all sub-industries reduces from 2009 growth level to zero growth in 2039 and after the emission peak continuously and steadily decreases to -1\% growth rate in 2049 (i.e., the annual abating rate is $1 \%$ in 2049); the 3rd and 4th path are similar to the 2nd path but the emission peak is changing to the year of 2029 and 2019, respectively; 5. The emission growth of all sub-industries maintains the half of their growth rate of emission in 2009 till 2049; 6. The dioxide carbon emission for each sub-industry remains the same as in 2009, i.e. the emission growth is to be zero ever since 2009; as for path 7, 8 and 9, a respective annually emission abating rate is $1 \%, 5 \%$ and $10 \%$, respectively, during the entire forecasting horizontal.

The forty five energy-saving and emission-abating policy pathes designed above will be introduced into the dynamic activity analytical model through direction vector as we will discuss in the following subsections.

\subsection{Dynamic Activity Analysis Model (DAAM)}

In this subsection, a novel dynamic activity analysis model (DAAM for short), not addressed so far, is proposed to simulate the effect of energy-saving and emission-abating regulation on economy in the long run, which is extended from the standard DDF and AAM provided by Chambers et al. (1996) and Chung et al. (1997) and applied by Färe et al. (2001), Jeon and Sickles (2004) etc. In this study, the decision-making units (DMU) are 38 two-digit sub-industries ( $i=1,2, \cdots, 38)$. The forecasting time span is from 2009 to $2049(t=2009,2010, \cdots, 2049)$. For each sub-industry, there are three types of input ( $j=1,2,3$, corresponding to capital, labor and energy), one type of desirable output (gross industrial output value, GIOV), and one type of undesirable output (dioxide carbon emission, CO2). The sample data sets between 1980 and 2008 used for simulation is based on Chen et al. (2011). The panel data for nearly 40 sub-industries, rather than aggregate data, significantly enhances the information that could be obtained to analyze microeconomic performance, particularly when examining the efficiency of each unit.

For $i$ th sub-industry, the column vectors of $\mathbf{x}^{i}, \mathbf{y}^{i}$ and $\mathbf{b}^{i}$ represent the inputs, desirable output and undesirable output, respectively. Then the production technology for $i$ th sub-industry at time point $t$ can be described by its output set:

$$
P\left(\mathbf{x}^{i}\right)=\left\{\left(\mathbf{y}^{i}, \mathbf{b}^{i},-\mathbf{x}^{i}\right): \mathbf{x}^{i} \text { can produce }\left(\mathbf{y}^{i}, \mathbf{b}^{i}\right)\right\}
$$

Same as Shephard distance function, DDF is also the representative function to describe such a production technology. DDF is nonparametric frontier production function approach which assumes that some units are more efficient than others in production. The principle of DDF is illustrated in Figure 2. The technology is represented by the output set $P(\mathbf{x})$ to which the output vector of A point $(\mathbf{y}, \mathbf{b})$ belongs. Shaephard's output distance function radially scales the original vector from point A proportionally to point $\mathrm{D}$ to describe the simultaneous increase of 
desirable and undesirable output. In contrast to this, more general DDF starts at A and scales in the direction along $\mathrm{ABC}$ to cature the increase of desirable outputs (or goods) and decrease of undesirable outputs (or bads) simultaneously which make it possible to investigate Porter hypothesis that allow for the possibility of crediting units for the reduction of pollutions. Formally, DDF is defined as

$$
\vec{D}_{o}\left(\mathbf{x}^{i}, \mathbf{y}^{i}, \mathbf{b}^{i} ; \mathbf{g}^{i}\right)=\sup \left\{\beta:\left(\mathbf{y}^{i}, \mathbf{b}^{i}\right)+\beta \mathbf{g}^{i} \in P\left(\mathbf{x}^{i}\right)\right\}
$$

where $\mathbf{g}$ is the direction vector in which outputs ae scaled. In standard case, $\mathbf{g}=(\mathbf{y},-\mathbf{b})$, as shown in Figure 2. $\beta$ is the maximum feasible expansion of the desirable outputs and contraction of the undesirable outputs when the expansion and contraction are identical proportions for a given level of inputs, which amounts to the value of DDF to be measured.

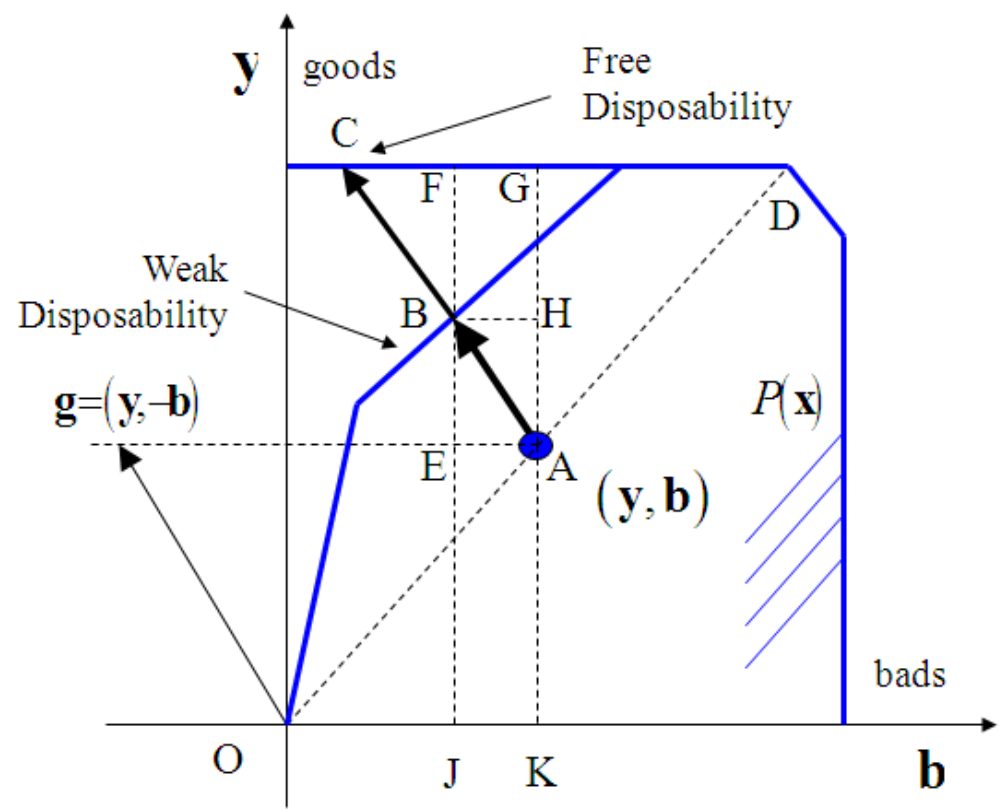

Figure 2. Principle of Directional Output Distance Function

\subsubsection{Production inefficiency and loss due to environmental regulation}

As shown in Figure 2, because the point A remains within the efficient production frontier, the inefficiencies resulted from such factors as high energy consumption and heavy emission give the producer the potential room to increase the output, given the inputs and current output, by saving energy and abating emission ${ }^{3}$. But whether the observation vector projects from the point A to point $\mathrm{B}$ or $\mathrm{C}$ depends on the weak or free disposal assumption of undesirable output. If assume that the undesirable output is strongly or freely disposal, that is, the disposability costs nothing, the producers will voluntarily get rid of the unwanted by-products, then potential output growth based on current desirable output is maximized which amounts to the distance function value $\beta_{s}$, i.e., the ratio of $\mathrm{AC} / \mathrm{Og}$. In this case, energy and environment impose no restriction on output, then the production in point $\mathrm{C}$ is the most efficient. However, it's impossible to cost nothing to reduce

\footnotetext{
${ }^{3}$ In this case, The value of $\beta$ is greater than zero which tell us the sizes of inefficiencies for the unit.
} 
undesirable output in reality. The producers therefore are not willing to reduce the bads because the cost makes use of the important inputs and then translates into lost goods given inputs. The bads reduction only can be achieved by environmental regulation; corresponding to this, the more appropriate assumtion is weak disposability of undesirable output, the point A projecting into B on the frontier, which is the standard DDF, or referred to as environment regulatory AAM, the value being $\beta_{w}$ (equal to $\mathrm{AB} / \mathrm{Og}$ ). In this case, the potential goods growth is a tradeoff between more goods and less bads, bound to less than the maiximized $\beta_{s}$ corresponding to highest level of inefficiency under the strong disposability of bads.

The difference between $\beta_{w}$ and $\beta_{s}$ reflects the potential output loss caused by the observable lack of free disposability (more vividly, due to enforced regulation), i.e., $l=\beta_{w}-\beta_{s}<0$ (Boyd et al., 2002). The value of $l$ is analogous to the hyperbolic output loss measure introduced by Färe et al. (1989) and used by Boyd and McClelland (1999). The potential output loss $l$ and potential output growth $\beta_{w}$ reveal the extent of the win-win potential for each sub-industry, given current output at some time point. If potential $\beta_{w}$ exceeds or equals the absolute value of $l,|l|$, from the perspective of output, the win-win opportunity due to energy-saving and emission-abating regulation, described in Porter hypothesis, happens, to some extent suggesting that improved production efficiency can make up for the losses imposed by regulations; otherwise, environmental regulation does not lead to win-win development. This paper will make use of this method to find the best energy-saving and emission-abating path that leads to the win-win development potentials.

\subsubsection{Dynamic Activity Analysis Model (DAAM)}

As stated previously, the direction vector in standard DDF is $\mathbf{g}=(\mathbf{y},-\mathbf{b})$, and the value of DDF, $\beta$, captures the maximum feasible proportion that the goods $\mathbf{y}$ expand while the bads $\mathbf{b}$ contract based on current output level $(\mathbf{y}, \mathbf{b})$ (the negative sign of $\mathbf{b}$ indicating the decline of bads). To simulate the dynamic process of energy-saving and emission-reducing activity, in this paper, we introduce the time factor into above standard direction vector and re-define the output direction vector as $\mathbf{g}^{t}=\left(\mathbf{y}^{t},-\mathbf{b}^{t}\right)=\left[(1+u) \mathbf{y}^{t-1},-(1+v) \mathbf{b}^{t-1}\right], \quad$ where $\quad u \quad$ and $\quad v$ respectively represent the varying rate of current goods and bads relative to previous time point (positive or negative, or increasing or decreasing) which do amount to the growth rate of gross industrial output value and the growth or abating rate of dioxide carbon emission from 2009 to 2049 designed in Subsection 3.1 in this study. Similarly, the dynamic varying path for the $j$ th input vector is defined as $\mathbf{x}_{j}^{t}=\left(1+\sigma_{j}\right) \mathbf{x}_{j}^{t-1}$, where $\sigma_{j}$ is respective varying rate - for energy, 
it equaling the growth of energy consumption that matches above GIOV growth so as to reduce the energy intensity by 3\% annually, as designed also in Subsection 3.1; for the input of capital and labor, it simply assumed to keep the historical averaged growht between 1981 and 2008.

In terms of the newly defined dynamic direction vector, the technology in $t$ period and observation also in $t$ period, the linear programming of two kinds of DDF, weak and strong disposability of undesirable output, is specified respectively for $i$ th sub-industry as below.

Directional Distance function (weakly disposable bads)

$$
\begin{array}{ll}
\vec{D}_{o}^{t}\left(\mathbf{x}^{i, t}, \mathbf{y}^{i, t}, \mathbf{b}^{i, t} ; \mathbf{y}^{i, t},-\mathbf{b}^{i, t}\right)=\operatorname{Max}_{\lambda, \beta} \beta_{w} \\
\text { s.t. } \quad \\
\sum_{i=1}^{38} \lambda^{i} \mathbf{y}^{i, t} \geq\left(1+\beta_{w}\right)(1+u) \mathbf{y}^{i, t-1} \\
& \sum_{i=1}^{38} \lambda^{i} \mathbf{b}^{i, t}=\left(1-\beta_{w}\right)(1+v) \mathbf{b}^{i, t-1} \\
& \sum_{i=1}^{38} \lambda^{i} \mathbf{x}_{j}^{i, t} \leq\left(1+\sigma_{j}\right) \mathbf{x}_{j}^{i, t-1} \quad(j=1,2,3) \\
& \beta, \lambda^{i} \geq 0 \quad(i=1,2, \cdots, 38)
\end{array}
$$

In linear programming (3), $\beta=0$ means that the sub-industry lies on the possibility frontier and its production is efficient; while $\beta>0$ implies that the sub-industry is inefficient in production. The proportion of the sub-industries with $\beta>0$ to all sub-industries shows us how widespread the inefficiencies are in the industry we study, which is related to the win-win opportunities by environmental regulation. The inequality for goods in (3) makes it freely disposable which means that the goods can be disposed of without the use of any inputs and then without the decrease of bads. The bads is modelled with equality that makes it weakly disposable. The inequality specification of inputs illustrates also that the inputs are strongly disposable; that is, the increase of inputs will not cause the decrease of output. The intensity variable $\lambda^{i}$ is the weight assigned to each sub-industry when constructing the production frontier. As shown in linear programming (3), novel definition of dynamic output and input direction vector not only introduces all kinds of possible energy-saving and emission-abating pathes into DDF wery well to capture the regulatory behavior ${ }^{4}$ but also makes it possible to forecast the dynamic impact of energy-saving and emission-abating activity on economy. Therefore, we abuse terminology and refer to the extended DDF as dynamic (environmental regulatory) activity analysis model (DAAM), which distinguishes itself from the standard AAM in that it has introduced the lag operator into direction vector and corresponding DDF. The DAAM constructed hear has, to the best of our knowledge, not been addressed before our study.

Directional Distance function (strongly disposable bads)

\footnotetext{
${ }^{4}$ For example, varying emission abating rate can be inclued in our design, as opposed to most of studies in which only several fixed abating rates are set for scenarios simulation.
} 


$$
\begin{array}{ll}
\vec{D}_{o}^{t}\left(\mathbf{x}^{i, t}, \mathbf{y}^{i t}, \mathbf{b}^{i t} ; \mathbf{y}^{i t},-\mathbf{b}^{i t}\right)= & \operatorname{Max}_{\lambda, \beta} \beta_{s} \\
\text { s.t. } \quad & \sum_{i=1}^{38} \lambda^{i} \mathbf{y}^{i, t} \geq\left(1+\beta_{s}\right)(1+u) \mathbf{y}^{i, t-1} \\
& \sum_{i=1}^{38} \lambda^{i} \mathbf{b}^{i, t} \geq\left(1-\beta_{s}\right)(1+v) \mathbf{b}^{i, t-1} \\
& \sum_{i=1}^{38} \lambda^{i} \mathbf{x}_{j}^{i, t} \leq\left(1+\sigma_{j}\right) \mathbf{x}_{j}^{i, t-1} \quad(j=1,2,3) \\
& \beta, \lambda^{i} \geq 0 \quad(i=1,2, \cdots, 38)
\end{array}
$$

From the mathematical perspective, the equality constraint of undesirable output in linear programming (3) is changed into the same inequality constraint as on the desirable output to reveal the strong disposability of undesirable output in linear programming (4). As mentioned above, the difference of solutions between (3) and (4) measures the potential production loss due to energy-saving and emission-reducing activity.

\subsubsection{Malmquist-Luenberger Productivity Index (MLPI)}

The DAAM of DDF (3) with the weak disposal assumption of undesirable output models the energy-saving and emission-abating activity under environmental regulation; therefore, it can be used to measure the change of total factor productivity (TFP) and its decomposition, allowing for the energy and environment restriction, by calculating the Malmquist-Luenberger Productivity Index (MLPI). To the end, four different types of DDF must be solved for each sub-industry: two use observations and technology at time period $t$ and $t+1, \vec{D}_{o}^{t}\left(\mathbf{x}^{i, t}, \mathbf{y}^{i, t}, \mathbf{b}^{i, t} ; \mathbf{y}^{i, t},-\mathbf{b}^{i, t}\right)$ and $\vec{D}_{o}^{t+1}\left(\mathbf{x}^{i, t+1}, \mathbf{y}^{i, t+1}, \mathbf{b}^{i, t+1} ; \mathbf{y}^{i, t+1},-\mathbf{b}^{i, t+1}\right)$, the former illustrated in linear programming (3); and two use adjacent period, for example, $\vec{D}_{o}^{t}\left(\mathbf{x}^{i, t+1}, \mathbf{y}^{i, t+1}, \mathbf{b}^{i, t+1} ; \mathbf{y}^{i, t+1},-\mathbf{b}^{i, t+1}\right)$ calculated from $t$ period technology with the $t+1$ period observation, and $\vec{D}_{o}^{t+1}\left(\mathbf{x}^{i, t}, \mathbf{y}^{i, t}, \mathbf{b}^{i, t} ; \mathbf{y}^{i, t},-\mathbf{b}^{i, t}\right)$ calculated from $t+1$ period technology with the $t$ period observation. Then the Malmquist-Luenberger Productivity Index (MLPI) defined by Chung et al. (1997) can be computed using the following formulation:

$$
\begin{aligned}
M L P I^{t, t+1}= & {\left[\frac{1+\vec{D}_{o}^{t}\left(\mathbf{x}^{i, t}, \mathbf{y}^{i, t}, \mathbf{b}^{i, t} ; \mathbf{y}^{i, t},-\mathbf{b}^{i, t}\right)}{1+\vec{D}_{o}^{t}\left(\mathbf{x}^{i, t+1}, \mathbf{y}^{i, t+1}, \mathbf{b}^{i, t+1} ; \mathbf{y}^{i, t+1},-\mathbf{b}^{i, t+1}\right)}\right.} \\
& \left.\times \frac{1+\vec{D}_{o}^{t+1}\left(\mathbf{x}^{i, t}, \mathbf{y}^{i, t}, \mathbf{b}^{i, t} ; \mathbf{y}^{i, t},-\mathbf{b}^{i, t}\right)}{1+\vec{D}_{o}^{t+1}\left(\mathbf{x}^{i, t+1}, \mathbf{y}^{i, t+1}, \mathbf{b}^{i, t+1} ; \mathbf{y}^{i, t+1},-\mathbf{b}^{i, t+1}\right)}\right]^{1 / 2}
\end{aligned}
$$

The Malmquist-Luenberger index is the most widely used productivity index and is particularly attractive since it does not rely on prices, specifically the price of $\mathrm{CO} 2$ appeared in this study, in order to construct it. The MLPI can be decomposed as the product of two terms: the change of production efficiency (MLECH) and the change of technical progress (MLTCH); that is 


$$
M L P I^{t, t+1}=M L E C H^{t, t+1} \cdot M L T C H^{t, t+1}
$$

where,

$$
\begin{gathered}
\operatorname{MLECH}^{t, t+1}=\frac{1+\vec{D}_{o}^{t}\left(\mathbf{x}^{i, t}, \mathbf{y}^{i, t}, \mathbf{b}^{i, t} ; \mathbf{y}^{i, t},-\mathbf{b}^{i, t}\right)}{1+\vec{D}_{o}^{t+1}\left(\mathbf{x}^{i, t+1}, \mathbf{y}^{i, t+1}, \mathbf{b}^{i, t+1} ; \mathbf{y}^{i, t+1},-\mathbf{b}^{i, t+1}\right)} \\
\operatorname{MLTCH}^{t, t+1}=\left(\frac{1+\vec{D}_{o}^{t+1}\left(\mathbf{x}^{i, t+1}, \mathbf{y}^{i, t+1}, \mathbf{b}^{i, t+1} ; \mathbf{y}^{i, t+1},-\mathbf{b}^{i, t+1}\right)}{1+\vec{D}_{o}^{t}\left(\mathbf{x}^{i, t+1}, \mathbf{y}^{i, t+1}, \mathbf{b}^{i, t+1} ; \mathbf{y}^{i, t+1},-\mathbf{b}^{i, t+1}\right)} \cdot \frac{1+\vec{D}_{o}^{t+1}\left(\mathbf{x}^{i, t}, \mathbf{y}^{i, t}, \mathbf{b}^{i, t} ; \mathbf{y}^{i, t},-\mathbf{b}^{i, t}\right)}{1+\vec{D}_{o}^{t}\left(\mathbf{x}^{i, t}, \mathbf{y}^{i, t}, \mathbf{b}^{i, t} ; \mathbf{y}^{i, t},-\mathbf{b}^{i, t}\right)}\right)^{1 / 2}
\end{gathered}
$$

If $M L P I>1$, it means that TFP grows over the adjacent period; while $M L P I<1$ indicates that TFP declines.

\section{FORECASTING ANALYSIS}

\subsection{Simulate the Win-Win Prospect under Different Energy-Saving and Emission-Abating Pathes}

Table I reports the potential industrial output growth $\beta_{w}$, loss $l$ and corresponding net value of loss averaged over the entire forecasting period under totally forty five environmental regulatory pathes combined by five energy-saving scenarios and nine emission-reducing scenarios ${ }^{5}$.

Seen from Table I, the potential output growth, output loss and net value of loss caused by energy-saving and emission-reducing exhibit a quite regular pattern in distribution of their values. With the increase of GIOV growth, the magnitude of potential output growth decreases gradually from about $73 \%$ in the group with $4 \%$ of GIOV growth to a bit more than $60 \%$ with $10 \%$ of GIOV growth. Therefore, the more rapid growth of industry will reduce the widespread extent of production inefficiencies, leading to the shrinking of improving space for potential output growth. However, the potential output loss brought by energy save and emission reduction keeps a roughly rising trend (though some values cross among the groups). Thus, the comparison between the potential output growth and loss enables us to see that the net value of output loss increases in fact from the range of $[-18.12 \%,-170.71 \%]$ in the group with $4 \%$ of GIOV growth to [-36.41\%, $-185.23 \%$ ] in the group of $10 \%$ GIOV growth. Such a evidence implies that the optimal path of energy save and emission reduction must be in the group with lower growth rate of gross industrial output value.

Table I classifies the former four moderate abating pathes as the gradually abating group and the latter five strong abating pathes as the sharp abating group. Obviously, as the abating strenth enhances from 1st path to 9th path, the potential output growth varies not much but the output loss increases sharply from [-91.55\%, $-97.09 \%]$ for path 1 to $[-244.64 \%, 248.87 \%]$ for path 9 . The corresponding increase of net loss indicates that the optimal energy-saving and emission-abating path must be in the gradual abating group. The lowest value of net loss in each GIOV group is

\footnotetext{
${ }^{5}$ For the convenience of report, Table I does not report the result of the group with $12 \%$ of GIOV Growth, in which the same trend as the rest of Table I follows. Particularly, the potential net values of loss in this group are greater than the former four GIOV groups; thus, there exists no optimal energy-saving and emission-abating path in this group.
} 
marked boldly in Table I. It is easy to pin down that the lowest value among all groups is - $17.93 \%$ in the group with $4 \%$ of GIOV growth which corresponds to path 3. Considering that economic development is the prior task and then the growth rate of gross industrial output cannot be too slow in China, we finally choose the 2nd path in the group with $6 \%$ of GIOV growth, corresponding to the lowest net loss $-22.95 \%$, as the best energy-saving and emission-abating path for Chinese industry in the next forty years, in which, the matching growth of energy consumption consistent with the target of annual $3 \%$ reduction in energy intensity is $2.8 \%{ }^{6}$. As stated previously, allowing for China's state condition fully, the chosen best path for sub-industries belongs to gradual abating group that evenly abates the dioxide carbon emission from their respective emission growing rate in the year of 2009 to zero growth in 2039 (i.e., the peak of emission for all sub-industries) and then evenly to abating rate of $1 \%$ in 2049 , the end of our forecasting period. Since all the potential net loss shown in Table I are negative, it seems that all pathes cannot lead to the win-win development suggested by Porter hypothesis, even though the best energy-saving and emission-abating path chosen above.

Table I Win-Win Development Forecasts Corresponding to Different Energy-Saving and Emission-Abating Pathes (\%)

\begin{tabular}{|c|c|c|c|c|c|c|c|c|}
\hline \multirow{2}{*}{\multicolumn{3}{|c|}{ Dioxide Carbon Abatement Pathes }} & \multicolumn{3}{|c|}{ GIOV Growth, $4 \%$} & \multicolumn{3}{|c|}{ GIOV Growth, $6 \%$} \\
\hline & & & \multirow{2}{*}{\multicolumn{2}{|c|}{$\begin{array}{cc}\beta w & l=\beta w-\beta s \\
73.43 & -91.55\end{array}$}} & \multirow{2}{*}{$\begin{array}{c}\text { Net Value } \\
-18.12\end{array}$} & \multirow{2}{*}{\multicolumn{2}{|c|}{$\begin{array}{cc}\beta w & I=\beta w-\beta s \\
69.46 & -92.42\end{array}$}} & \multirow{2}{*}{$\frac{\text { Net Value }}{-22.96}$} \\
\hline \multirow{4}{*}{$\begin{array}{c}\text { Gradual } \\
\text { Abatement }\end{array}$} & Path 1 & Emission Peak in 2049 & & & & & & \\
\hline & Path 2 & Emission Peak in 2039 & 73.52 & -91.46 & -17.94 & 69.47 & -92.43 & -22.95 \\
\hline & Path 3 & Emission Peak in 2029 & 73.52 & -91.45 & -17.93 & 69.46 & -92.50 & -23.04 \\
\hline & Path 4 & Emission Peak in 2019 & 73.41 & -91.59 & -18.18 & 69.46 & -92.48 & -23.02 \\
\hline \multirow{5}{*}{$\begin{array}{c}\text { Sharp } \\
\text { Abatement }\end{array}$} & Path 5 & Half of 2009 Emission Growth & 74.41 & -106.58 & -32.17 & 70.30 & -101.82 & -31.53 \\
\hline & Path 6 & Keeping 2009 Emission Level & 74.55 & -155.68 & -81.14 & 70.17 & -152.12 & -81.95 \\
\hline & Path 7 & Abating 1\% Annually & 74.71 & -174.94 & -100.23 & 69.92 & -176.01 & -106.09 \\
\hline & Path 8 & Abating 5\% Annually & 74.81 & -201.17 & -126.37 & 69.96 & -203.87 & -133.91 \\
\hline & Path 9 & Abating 10\% Annually & 73.93 & -244.64 & -170.71 & 70.11 & -248.87 & -178.77 \\
\hline \multirow{2}{*}{\multicolumn{3}{|c|}{ Dioxide Carbon Abatement Pathes }} & \multicolumn{3}{|c|}{ GIOV Growth, $8 \%$} & \multicolumn{3}{|c|}{ GIOV Growth, $10 \%$} \\
\hline & & & $\beta w$ & $I=\beta w-\beta s$ & Net Value & $\beta w$ & $l=\beta w-\beta s$ & Net Value \\
\hline \multirow{4}{*}{$\begin{array}{c}\text { Gradual } \\
\text { Abatement }\end{array}$} & Path 1 & Emission Peak in 2049 & 63.51 & -92.95 & -29.44 & 60.68 & -97.09 & -36.41 \\
\hline & Path 2 & Emission Peak in 2039 & 63.62 & -92.71 & -29.09 & 60.67 & -97.10 & -36.43 \\
\hline & Path 3 & Emission Peak in 2029 & 63.52 & -92.81 & -29.29 & 60.66 & -97.35 & -36.69 \\
\hline & Path 4 & Emission Peak in 2019 & 63.48 & -92.90 & -29.42 & 60.68 & -97.24 & -36.56 \\
\hline \multirow{5}{*}{$\begin{array}{c}\text { Sharp } \\
\text { Abatement }\end{array}$} & Path 5 & Half of 2009 Emission Growth & 67.46 & -105.09 & -37.63 & 64.38 & -111.17 & -46.80 \\
\hline & Path 6 & Keeping 2009 Emission Level & 65.20 & -158.39 & -93.19 & 62.49 & -158.51 & -96.02 \\
\hline & Path 7 & Abating 1\% Annually & 65.59 & -178.36 & -112.77 & 62.72 & -174.66 & -111.94 \\
\hline & Path 8 & Abating 5\% Annually & 65.72 & -203.70 & -137.98 & 63.19 & -202.69 & -139.50 \\
\hline & Path 9 & Abating 10\% Annually & 65.53 & -245.96 & -180.43 & 63.17 & -248.40 & -185.23 \\
\hline
\end{tabular}

\footnotetext{
${ }^{6}$ Another reason to choose the path with the lowest net loss in the group of $6 \%$ GIOV growth, instead of four pahtes with lower net loss in the group of $4 \%$ GIOV growth, is that if sub-optimalpath could lead to win-win opportunities, the optimal path will be more likely to cause the win-win development, which has already been confirmed in this study but not reported to save the space.
} 
The findings in Table I are consistent with most other researches. Schaltegger and Synnestvedt (2002) argue that not merely the level of environmental performance, but mainly the kind of environmental management approach with which a certain level is achieved, influences the economic outcome, thus, the economic success resulted from the environmental protection finally depends on the chosen kind of regulatory approach rather the level. It's suggestion that research and business practice should focus less on general correlations and more on the effect of different environmental management approaches on economic performance is consistent with the methodology used in our studies. Roughgarden and Schneider (1999) use the dynamic integrated climate-economy (DICE) model to calculate an optimal control rate or carbon tax and suggest that an efficient policy for slowing global warming would incorporate only a relatively modest amount of abatement of greenhouse gas emissions, via the mechanism of a small carbon tax. Chen et al. (2004) find that the earlier the emission reducing policy is implemented the greater the GDP loss will be. If the start of the emission reductions is the year of 2030, 2020 or 2010 instead of 2040, then the undiscounted total GDP losses in thw whole planning horizon would be 0.58-0.74, 1.00-1.32, or 1.10-1.83 times higher. Kuosmanen et al. (2009) suggest that if one is only interested in greenhouse gases (GHG) abatement at the lowest economic cost, then equal reduction of GHGs over time is preferred. These researches all support the gradual or moderate emission abatement. Similar to the idea of our paper that there is a close relationship between emission reduction and development, Reddy and Assenza (2009) also suggest that the integration of climate policies with those of development priorities that are vitally important for developing countries and stress the need for using sustainable development as a framework for climate change policies.

Of course, the optimal path chosen here means that the combination of a relatively high growth of output and energy consumption maybe have a relation with the traditional industry development model that it is hazardous to the win-win development of China's industry. An adjustment on the speed of output growth and a moderate reduction of energy consumption may be more beneficial to the structural reconstruction, development model transformation and sustainable development for China's industry in the future.

\subsection{The Impact of Best Energy-Saving and Emission-Abating Path on Future Potential Output}

Murty and Kumar (2003) pointed out that the win-win opportunities from the environmental regulation could be found more in some industries and less in others, and the studies for specific industries could help us to identify the industries with no such opportunities so that the monitoring and enforcement could be directed to those industries in which incentives are absent. As a matter of fact, it is also the reason why we focus on the analysis of China's 38 two-digit sub-industries instead of merely the aggregated industry. Therefore, proceeding along the optimal path of energy save and emission reduction chosen in previous subsection, this subsection further simulates the potential output growth and loss for all sub-industries in the following 40 years. Figure 3 illustrates the forecasting prospects for each sub-industry ${ }^{7}$.

Table I shows that the averaged net losses brought by different regulatory pathes are all negative, even though by the best energy-saving and emission-abating path. However, if we

\footnotetext{
${ }^{7}$ For the convenience, only 35 sub-industries are included in this figure, excluding production and supply of water (heavy industry), manufacture of chemical fibers (light industry) and other industries. The win-win forecasting prospect of the three sub-industries is also in accord with the conclusion of this paper.
} 
analyze the individual sub-industry at different time point rather the aggregated industry, the situation will be totally another story. The dashed line in Figure 3. represents absolute value of potential output loss caused by energy save and emission reduction and the real line represents potential output growth. Found from this figure, the potential output loss exhibits a declining trend for all sub-industries and the potential output growth of most sub-industries does not change much. Except for six sub-industries such as ferrous ores mining, apparel manufacturing, leather manufacturing, cultural articles manufacturing, plastic manufacturing and gas production and supply, the potential loss for all the other sub-industries decreases continuously and then appears to be smaller than potential output growth at some time point before 2049. This indicates that for most sub-industries, the energy-saving and emission-abating activity can bring the win-win development opportunity that the potential output growth exceeds the potential output loss. Even to the above exceptional six sub-industries, their potential output losses tend to decline, too, and are bound to be lower than the potential growth at certain time after the year of 2049, leading to expecting win-win development.

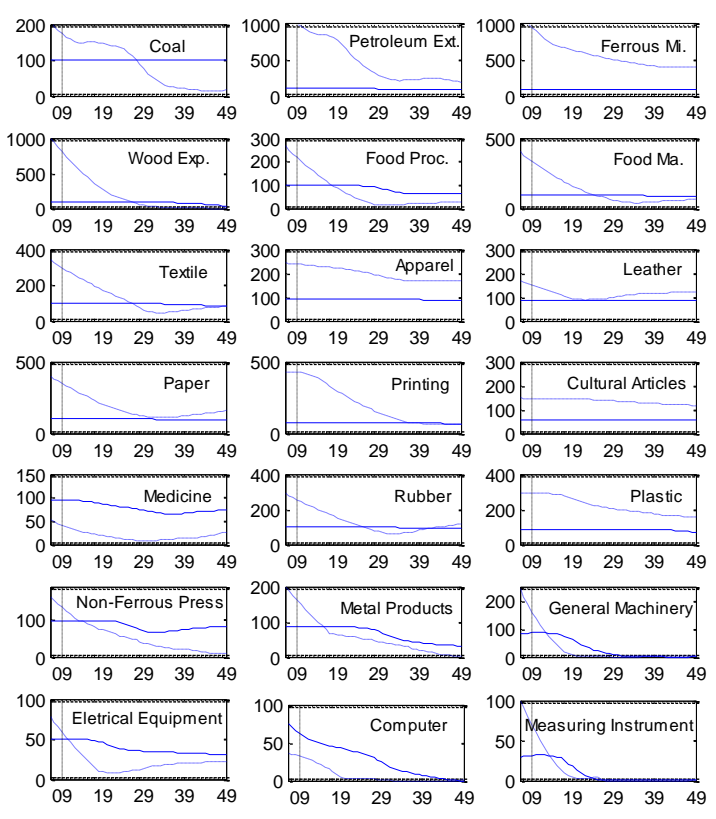
Dashed Line: Potential Output Loss; Solid Line: Potential Output Growth
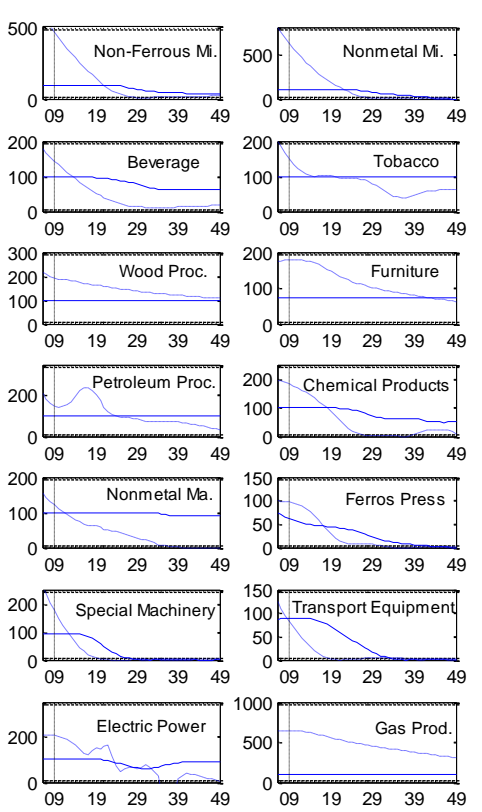

YAxis:\%; X Axis: Year

Figure 3. Sub-Industrial Win-Win Development Forecasts Under the Best Energy-Saving and Emission-Abating Path (2009-2049)

The reason why the averaged net values of potential loss for all pathes, even the best one, are minus is that all the sub-industries (except medicine manufacturing, and communication equipment and computer manufacturing) have large potential loss in the nearer future. It is thus clear that the aggregation analysis is undependable and even leads you to the opposite conclusion. Specifically, the potential output loss of those energy and emission intensive sub-industries such as petroleum extraction, ferrous ores mining, wood exploiting, and gas production and supply are particularly large, which should be one of the causes of the negative weighted potential loss for aggregated industry. Moreover, what we care about the energy save and emission reduction is its final influential level instead of accumulative effect; hence, the high potential loss in the nearer 
future is just meaningful for that period and useless for the analysis on the future opportunity of win-win development. As mentioned above, the medicine manufacturing, and communication equipment and computer manufacturing are the only two sub-industries maintaining the win-win development over the whole predicting time span. As for general machinery manufacturing, Special machinery manufacturing, transport equipment manufacturing and measuring instrument and machinery, they realize efficient production around the year of 2029, which means they are on the production fiontier and have no space to improve the potential output growth no matter there is energy save and emission reduction or not. All in all, the sub-industrial simulation results shown in Figure 3 manifests that, from the perspective of potential output, energy-saving and emission-abating can bring costs on output which means that Porter hypothesis will not be satisfied in the very nearer future, but when the time moves on, it will lead to the win-win development possibility for China's industry, finally supporting the Porter hypothesis.
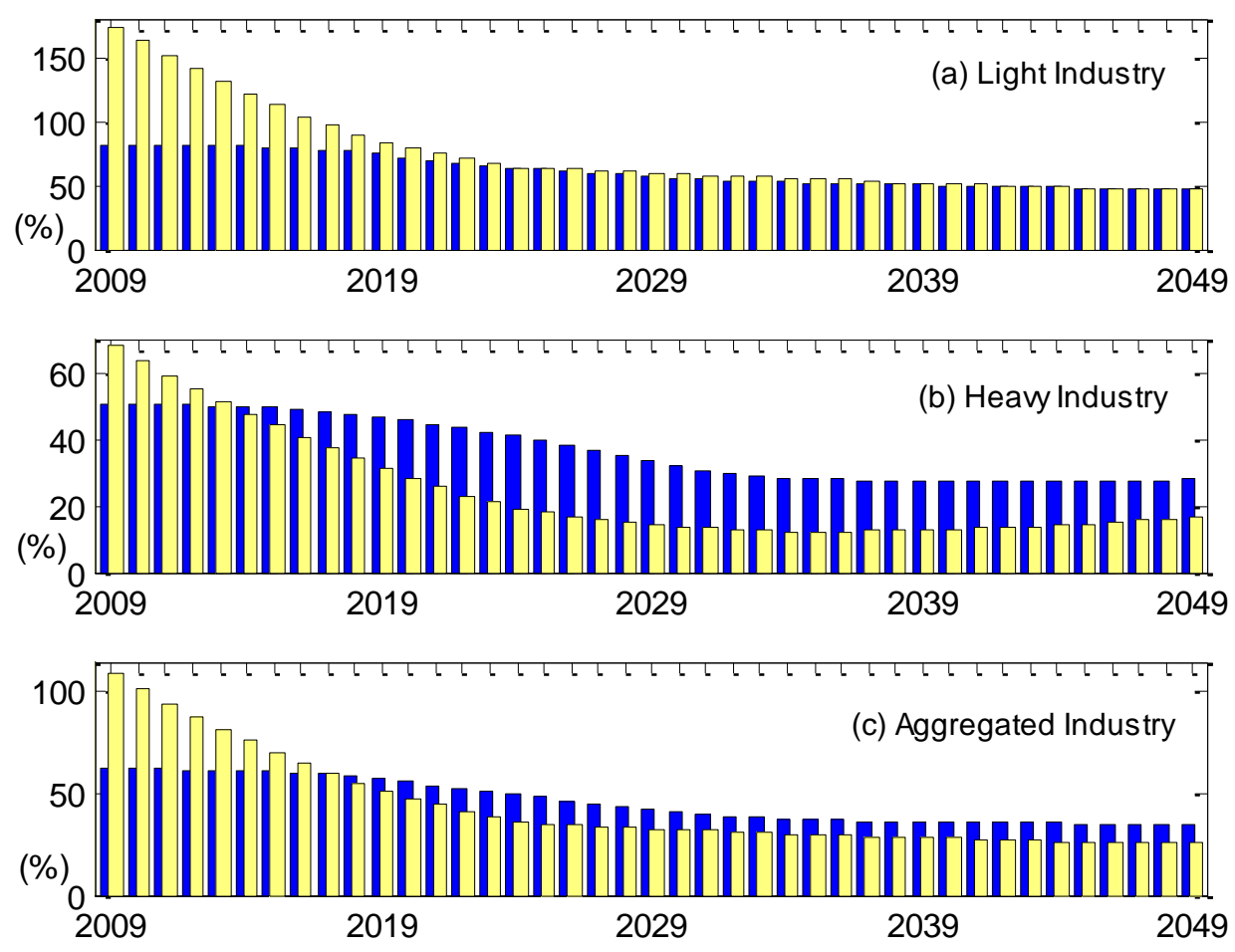

Light Color Bar: Potential Output Loss; Deep Color Bar: Potential Output Growth

Figure 4. Averaged Industrial Win-Win Development Forecasts Under the Best Energy-Saving and Emission-Abating Path (2009-2049)

According to the theory in Chenery et al. (1986) and current empirical work in Chen et al. (2011), the standard perception of industrialization is a general shift in relative importance from light to heavy industry. Light industry is of great importance normally at the early stage of industrialization and labor-intensive in nature with relatively low ratios of capital to labor; while heavy industry is at the middle or late stage and capital-intensive with relatively high ratios of capital to labor. Therefore, we divide all sub-industries into light and heavy industrial groups according to the ranking of capital to labor ratio (K/L) in 2008. That is, the light industrial group corresponds to the top half of sub-industries with the lower $\mathrm{K} / \mathrm{L}$ ratio, and the heavy industry to the last half of sub-industries with the larger $\mathrm{K} / \mathrm{L}$ ratio. We refer to them as light industry and 
heavy industry in brief from now on in this paper. This is because 38 sub-industrial patterns of potential output growth and loss are too complicated to see clearly all at once, and sometimes we want to observe the difference just between the light and heavy industry instead. Figure 4 depicts the weighted average potential output loss (bar with light color) and output growth (deep color) for light and heavy industry (panel a and b) and aggregated industry (panel c) corresponding to the best environmental regulatory path, in which the sub-industrial weight is its respective share of gross industrial output value.

Seen from Figure 4, in light industry, the averaged potential loss declines prominently from $-173.95 \%$ in 2009 to $-46.85 \%$ in 2049 while the potential output growth decreases less evidently from $80.51 \%$ in 2009 to $46.86 \%$ in 2049 ; in heavy industry, the corresponding varying range of averaged potential output loss, [-67.95\%, -16.32\%], and growth, [50.62\%, 27.75\%], is much less than that in light industry. Apparently, both the potential output loss and growth for light industry are high whereas for heavy industries they are the opposite. The light industry does not reach a comparable level for potential output loss and growth until 2024 and keeps the similar situation to 2049, just right meeting the win-win development condition. But for the heavy industry, the win-win situation is reached ever since the earlier year of 2014 and the potential output growth holds a large advantage over the loss. Therefore, heavy sub-industries are the beneficiaries of energy save and emission reduction, but light sub-industries are also not the losers. For the aggregated industry, the potential output loss declines from $-108.72 \%$ in 2009 to $-25.55 \%$ in 2049 , the potential output growth decreases from $62.11 \%$ in 2009 to $34.97 \%$ at the end of the forecasting period -being between that of light and heavy industry. Since heavy sub-industries have the higher weights, the varying pattern of the potential output for aggregated industry is dominated by and more similar to that of heavy industry - realizing the win-win development in the year of 2018 with a distinguished advantage.

\subsection{The Effect of Best Energy-Saving and Emission-Abating Path on Future Industrial Productivity}

Sickles and Streitwieser (1998) have once investigated the impact of regulatory environment such as partial and gradual decontrol of natural gas prices on both the output change, technology and productivity in the interstate natural gas pipeline industry. Following this, this subsection also addresses the impact of optimal energy-saving and emission-abating policy on the foreseeable change of productivity, technical progress and efficiency, in addition to the potential output, in Chinese industry. Adopting the same group classification and weights as in Figure 4, Figure 5 exhibits the averaged changing trends of total factor productivity (i.e. the Malmquist-Luenberger Productivity Index, MLPI) and its decompositions, MLECH and MLTCH, under the best path of energy save and emission reduction for light and heavy industry (panel a and b) and aggregated industry, respectively. Three subfigures show a similar pattern. That is, China's industrial TFP before the year of 2032 or 2033 is mainly influenced by production efficiency in which the catching-up effect of adoption of the frotier technologies due to the environmental regulation is very obvious. When the production efficiency attaches its utmost limits and the catching-up energy is almost released, the technical progress begins to serve as the major propelling force through gradual accumulation and assimilation, i.e., the change of TFP after the year of 2033 mainly affected by the technical progress. Therefore, as illustrated in Figure 5, the behavior of the overall TFP index shows that the industrial development has generally shifted in a win-win 
fashion.
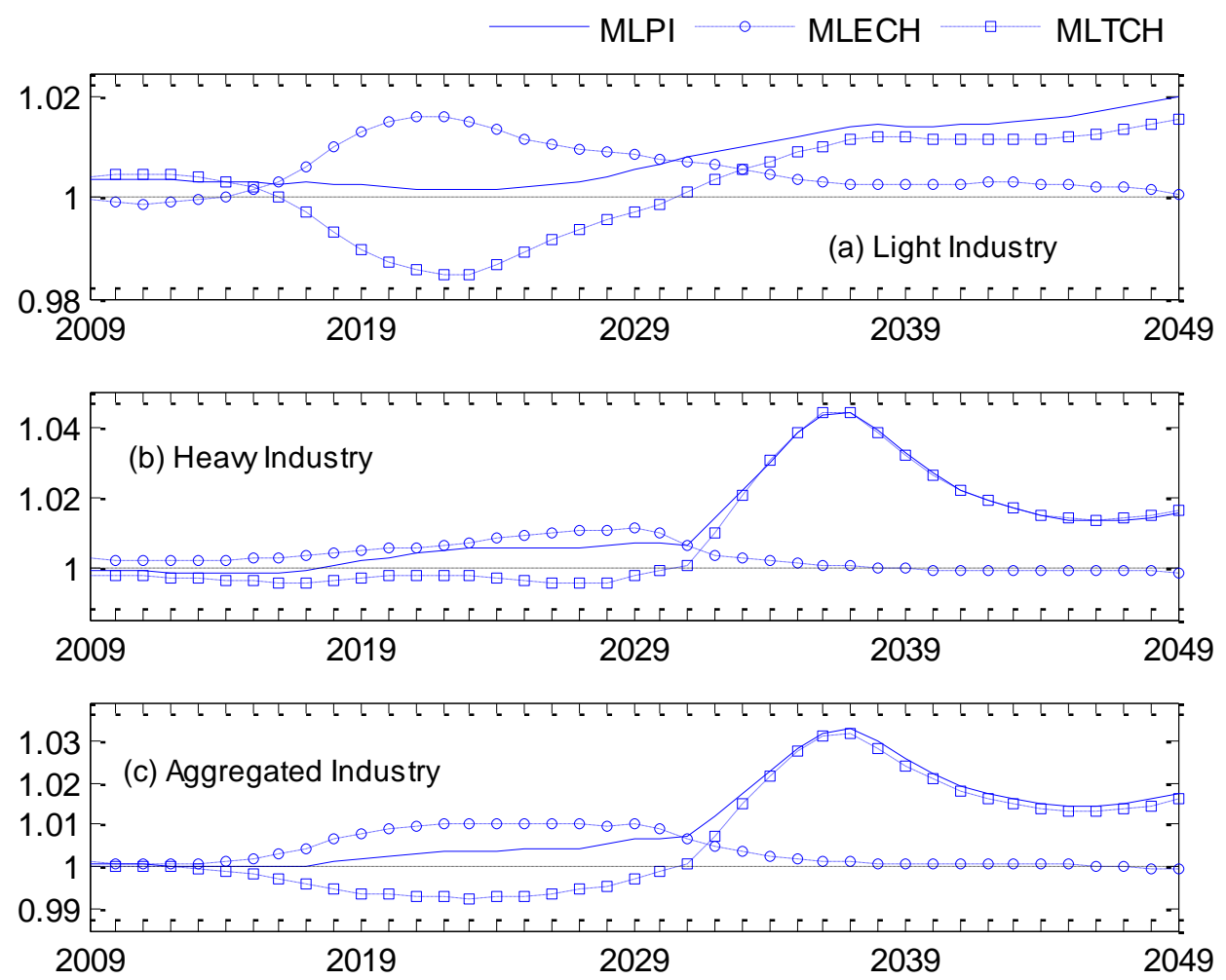

Figure 5. Averaged Productivity Forecasts and its Decomposition Under the Best Energy-Saving and Emission-Abating Path (2009-2049)

More specifically, at the early stage, energy-saving and emission-abating policy mainly negatively affect the industrial technical progress, and more on light industry than on heavy industry. For instance, for light industry, the level of technical progress in 2023 is just $98.48 \%$ of 2022, attaching the largest backward magnitude of production frontier, $-1.52 \%$, over the whole forecasting period; the largest backward extent of technical progress for heavy industry is $-0.5 \%$ in 2026 and the largest one for the aggregated industry is $-0.74 \%$ in 2024 . However, due to the obvious catching-up effect and improved production efficiency (at the peak of efficiency improvement, the index of MLECH of light industry in 2022 is 1.016 times of the previous year; that of heavy industry in 2029 is 1.011 times of that in 2028; that of the aggregated industry in 2023 is 1.01 times of the previous year), the TFP growth will keeps a increasing trend at the earlier forecasting phase. After 2031, the negative effect of environmental regulation on technical progress fades gradually and turns to be positive; three or four years latter, the catching-up effect disappears, especially in heavy industry; in around 2037, the technical progress reaches its peak due to the long-term introduction, absorbtion, adoption and innovation of the advanced technologies - in particular in energy and emission intensive heavy industry, the technical progress in 2036 reaching 1.044 times of 2035; after that, the technical progress and productivity for light industry keep stable with slight increase, and those for heavy industry and the aggregated industry, dominated by heavy industry, will drop firstly and then rise more steadily due to the enhancement of abating strenth after the peak of dioxide carbon emission in 2039. In a word, from 
the perspective of productivity, energy-saving and emission-abating activity has a negative impact on industrial technical progress at earlier stage, but positive on production efficiency and combined total factor productivity. During the entire forecasting period from 2009 to 2049, the TFP grows steadily with the annually averaged growth rate of $0.81 \%$ for light industry, $1.11 \%$ for heavy industry and $1 \%$ for the aggregated industry. In the year of 2049, the growth rate for light, heavy and aggregated industry will reach $2.02 \%, 1.54 \%$ and $1.72 \%$, respectively, in terms of our forecasting. This is a win-win development prospect since the productivity is grown and the targets of energy save and emission reduction are also achieved.

\section{CONCLUSION}

To challenge the global warming and boost the development model transformation, energy-saving and emission-abating and developing the low carbon economy have become the necessary approach for all the countries to achieve the sustainable economic development (Chen, 2011). However, the energy save and environment protection will seize the important materials originally planned to normally produce, causing the declination of the desirable output and competitiveness, especially in the recovery period from the financial crisis. The conflicting views are also reflected in academic area, i.e., if in favor or against the Porter hypothesis. This paper makes use of the directional distance function that precisely embodies the spirit of Porter hypothesis that the goods increase and bade decrease simultaneously and proposes a novel dynamic activity analysis model (DAAM) to forecast the win-win development possibilities for Chinese sub-industries between 2009 and 2049, to investigate the existence of Porter hypothesis in China.

From the perspective of potential output, the empirical results show that energy save and emission reduction can cause bigger potential output loss in an early stage; but in long run, the loss will decline gradually and become lower than potential output growth finally, achieving the win-win development prospect stated in Porter hypothesis. Of course, compared with light industry, there exists a bigger win-win opportunity resulted from the environmental regulation in heavy industry and the aggregated industry. For example, the potential output loss and growth for the aggregated industry in 2049 attain $-25.55 \%$ and $34.97 \%$, respectively, finally leading to $9.42 \%$ of net growth of potential output. From the viewpoint of productivity, the prediction analysis manifests that energy-saving and emission-reducing policy will have a larger negative impact on industrial technical progress at an early stage, especially for light industry; however, due to the obvious catching-up effect and increasing production efficiency in the first half forecasting period and the rising technical progress dominated in the second half period, the industrial TFP is not negatively influenced and always maintains a steadily but gradually increasing trend. During the whole forecasting period from 2009 to 2049 , the annually averaged growth rate of productivity is $0.81 \%$ for light industry, $1.11 \%$ for heavy industry and $1 \%$ for the aggregated industry. Overall, although energy-saving and emission-abating regulation will cause certain loss at an early stage, in the long run, it will not only reach the target of improving environment quality but also increase the output and productivity, finally leading to the win-win development in the next 40 years. Our forecasting analysis in this paper favors the Porter hypothesis.

\section{ACKNOWLEDGEMENTS}

The work is sponsored by Center for Applied Statistics and Economics (CASE) at Humboldt-Universität zu Berlin and Deutsche Forschungsgemeinschaft through the SFB 649 
"Economic Risk". The sponsorships by Program for New Century Excellent Talents in University (NCET), Shanghai Leading Academic Disciplines Project (\#B101), and Project 985 at Fudan University are also gratefully acknowledged.

\section{REFERENCES}

Ambec S, Barla P. 2002. A theoretical foundation of the Porter hypothesis. Economics Letters 75(3): 355-360.

Beaumont NJ, Tinch R. 2004. Abatement cost curves: a viable management tool for enabling the achievement of win-win waste reduction strategies? Journal of Environmental Management 71(3): 207-215.

Boyd GA, McClelland JD. 1999. The impact of environmental constraints on productivity improvement in integrated paper plants. Journal of Environmental Economics and Management 38: 121-142.

Boyd GA, Tolley G, Pang J. 2002. Plant level productivity, efficiency, and environmental performance of the container glass industry. Environmental and Resource Economics 23: 29-43.

Cai F, Du Y, Wang M. 2008. The Political Economy of Emission in China: Will a Low Carbon Growth Be Incentive Compatible in Next Decade and Beyond? Economic Research Journal (Jing-Ji Yan-Jiu) 6: 4-11.

Cerin P. 2006. Bringing economic opportunity into line with environmental influence: A discussion on the Coase theorem and the Porter and van der Linde hypothesis. Ecological Economics 56(2): 209-225.

Chambers R, Chung YH, Färe R. 1996. Benefit and Distance Function. Journal of Economic Theory 70: 407-419.

Chen S. 2009. Engine or Drag: Can High Energy Consumption and CO2 Emission Drive the Sustainable Development of Chinese Industry? Frontier of Economics in China 4: 548-571.

Chen S. 2011. The Abatement of Carbon Intensity in China: Factor Decomposition and Policy Implications. The World Economy, In Press.

Chen S, Jefferson GH, Zhang J. 2011. Structural Change, Productivity Growth and Industrial Transformation in China. China Economic Review, In Press.

Chen W, Gao P, He J. 2004. Impacts of Future Carbon Reductions on the Chinese GDP Growth. Journal of Tsinghua University (Science and Technology) 44(6): 744-747.

Chenery HB, Robinson S, Syrquin M. 1986. Industrialization and Growth: A Comparative Study. New York: Oxford University Press.

Chung YH, Färe R, Grosskopf S. 1997. Productivity and undesirable outputs: A directional distance function approach. Journal of Environmental Management 51: 229-240.

Färe R, Grosskopf S, Lovell K, Pasurka C. 1989. Multilateral Productivity Comparisons When Some Outputs are Undesirable: A nonparametric Approach. Review of Economics and Statistics 71: 90-98.

Färe R, Grosskopf S, Pasurka Jr. CA. 2001. Accounting for air pollution emissions in measures of state manufacturing productivity growth. Journal of Regional Science 41(3): 381-409.

Faucheux S, Nicolaï I. 1998. Environmental technological change and governance in sustainable development policy. Ecological Economics 27: 243-256.

Feichtinger G, Hartl RF, Kort PM, Veliov VM. 2005. Environmental policy, the porter hypothesis and the composition of capital. Journal of Environmental Economics and Management 50(2): 434-446.

Greaker M. 2006. Spillovers in the development of new pollution abatement technology: A new look at the Porter-hypothesis. Journal of Environmental Economics and Management 52(1): 411-420 .

Groom B, Grosjean P, Kontoleon A, Swanson T, Zhang S. 2010. Relaxing rural constraints: a ‘win-win' policy for poverty and environment in China? Oxford Economic Papers 62(1): 132-156.

Jaffe A, Peterson S, Portney P, Stavins R. 1995. Environmental regulation and the competitiveness of U.S. manufacturing: what does the evidence tell us? Journal of Economic Literature 33(1): 132-163.I

Jeon BM, Sickles RC. 2004. The role of environmental factors in growth accounting. Journal of Applied 
Econometrics 19(5): 567-591.

Karvonen M. 2001. Natural versus manufactured capital: win-lose or win-win? A case study of the Finnish pulp and paper industry. Ecological Economics 37(1): 71-85.

Kuosmanen T, Bijsterbosch N, Dellink R. 2009. Environmental cost-benefit analysis of alternative timing strategies in greenhouse gas abatement. Ecological Economics 68 (6): 1633-1642.

Lee CF, Lin SJ, Lewis C, Chang YF. 2007. Effects of carbon taxes on different industries by fuzzy goal programming: A case study of the petrochemical-related industries, Taiwan. Energy Policy 35(8): 4051-4058.

Lin JY. 2004. Is China's Growth Real and Sustainable? Asian Perspective 28: 5-29.

Managi S. 2006. Are there increasing returns to pollution abatement? Empirical analytics of the Environmental Kuznets Curve in pesticides. Ecological Economics 58 (3): 617-636.

Mohr RD. 2002. Technical Change, External Economies, and the Porter Hypothesis. Journal of Environmental Economics and Management 43(1): 158-168.

Murty MN, Kumar S. 2003. Win-win opportunities and environmental regulation: testing of porter hypothesis for Indian manufacturing industries. Journal of Environmental Management 67(2): 139-144.

Nugent JB, Sarma CVSK. 2002. The three E's-efficiency, equity, and environmental protection-in search of “win-win-win" policies: A CGE analysis of India. Journal of Policy Modeling 24(1): 19-50.

Palmer K, Oates WE, Portney PR. 1995. Tightening Environmental Standards: The Benefit-Cost or the No-Cost Paradigm. Journal of Economic Perspectives 9(4): 97-118.

Porter ME. 1991. America's Green Strategy. Scientific American 264(4): 168.

Porter ME, van der Linde C. 1995. Toward a New Conception of the Environment - Competitiveness Relationship. Journal of Economic Perspectives 9(4): 97-118.

Reddy BS, Assenza GB. 2009. The great climate debate. Energy Policy 37(8): 2997-3008.

Robins N, Clover R, Singh C. 2009. A climate for recovery: the colour of stimulus goes green. HSBC Global Research 25 February 2009 issue, 1-45.

Roughgarden T, Schneider SH. 1999. Climate change policy: quantifying uncertainties for damages and optimal carbon taxes. Energy Policy 27 (7): 415-429.

Schaltegger S, Synnestvedt T. 2002. The link between green and economic success: environmental management as the crucial trigger between environmental and economic performance. Journal of Environmental Management 65(4): 339-346.

Sickles RC, Streitwieser ML. 1998. An analysis of technology, productivity, and regulatory distortion in the interstate natural gas transmission industry: 1977-1985. Journal of Applied Econometrics 13(4): 377-395.

Xepapadeas A, De Zeeuw A. 1999. Environmental Policy and Competitiveness: The Porter Hypothesis and the Composition of Capital. Journal of Environmental Economics and Management 37(2): 165-182. 


\section{SFB 649 Discussion Paper Series 2012}

For a complete list of Discussion Papers published by the SFB 649, please visit http://sfb649. wiwi.hu-berlin.de.

001 "HMM in dynamic HAC models" by Wolfgang Karl Härdle, Ostap Okhrin and Weining Wang, January 2012.

002 "Dynamic Activity Analysis Model Based Win-Win Development Forecasting Under the Environmental Regulation in China" by Shiyi Chen and Wolfgang Karl Härdle, J anuary 2012. 